\title{
Panorama socioespacial dos produtores familiares rurais no Médio-Parnaíba
}

\section{piauiense}

\author{
Sociospace overview of rural family producers in the mid-region of Parnaíba in Piauí \\ Panorama socioespacial de productores familiares rurales en el Médio-Parnaíba piauiense
}

Recebido: 03/11/2021 | Revisado: 10/11/2021 | Aceito: 10/11/2021 | Publicado: 20/11/2021

\author{
Karen Veloso Ribeiro \\ ORCID: https://orcid.org/0000-0002-3944-6304 \\ Universidade Federal do Piauí, Brasil \\ E-mail: karenveloso29@hotmail.com \\ Emanuel Lindemberg Silva Albuquerque \\ ORCID: https://orcid.org/0000-0003-3051-3301 \\ Universidade Federal do Piauí, Brasil \\ E-mail: lindemberg@ufpi.edu.br \\ Roseli Farias Melo de Barros \\ ORCID: https://orcid.org/0000-0001-9767-5546 \\ Universidade Federal do Piauí, Brasil \\ E-mail: rbarros@ufpi.edu.br
}

\begin{abstract}
Resumo
A agricultura familiar se caracteriza pela inserção de pequenos produtores familiares nas unidades agrícolas, os quais estabelecem diferentes culturas, em pequenas propriedades de terra, com uso de tecnologia rudimentar e mão de obra familiar, destinando sua produção para o autoconsumo. Nessa perspectiva, objetivou-se representar os aspectos ambientais e socioeconômicos dos produtores familiares rurais do Médio-Parnaíba piauiense, para que tais informações sirvam de subsídio em tomadas de decisões no âmbito rural. A pesquisa foi conduzida em quatro localidades rurais, por meio de entrevista semiestruturada, totalizando 44 informantes, sendo os dados coletados, analisados pelo método de abordagem mista. Constatou-se que os agricultores entrevistados são majoritariamente do gênero masculino (39 indivíduos), de faixa etária adulta $(54,54 \%)$ e de baixa escolaridade $(54,54 \%)$. No quesito renda familiar, os proventos oriundos da agricultura não chegam a um salário-mínimo para 47,72\% dos participantes. Dentre os fatores que se associam ao êxodo rural destacam-se: busca por melhorias de condições de vida, escassez hídrica e o avanço do agronegócio, sobretudo, no alto curso fluvial. Depreendeu-se que a baixa escolarização reflete diretamente na renda mensal percebida pelos agricultores familiares rurais, que por consequência repercute na infraestrutura do seu local de produção, nos mecanismos de uso e manejo da terra, bem como nos rendimentos dos produtos obtidos, denotando, portanto, forte correlação entre as variáveis socioambientais e o modo de desenvolvimento agrícola desempenhado pelo pequeno produtor rural.
\end{abstract}

Palavras-chave: Bacia hidrográfica; Sócioeconomia; Agricultura familiar.

\begin{abstract}
Family farming is characterized by the insertion of small family producers in agricultural units, who establish different cultures, on small properties of land, using rudimentary technology and family labor, allocating their production for self-consumption. From this perspective, the goal was to represent the environmental and socioeconomic aspects of rural family producers in the mid-region of Parnaíba in Piauí, so that such information could serve as a subsidy in decision-making in the rural space. The research was conducted in four rural locations, through semi-structured interviews, totaling 44 informants, and the collected data were analyzed using the mixed approach method. It was found that the interviewed farmers are mostly male (39 individuals), of adult age (54.54\%) and of low education (54.54\%). In terms of family income, earnings from agriculture do not reach a minimum wage for $47.72 \%$ of the participants. Among the factors associated with the rural exodus, the following can be highlighted: search for improvements in living conditions, water scarcity and the advancement of agribusiness, especially in the upper river course. It was inferred that low education directly reflects on the monthly income perceived by rural family farmers, which consequently has an impact on the infrastructure of their production site, on the mechanisms of land use and management, as well as on the income of the products obtained, thus denoting strong correlation between socioenvironmental variables and the mode of agricultural development performed by the small rural producer.
\end{abstract}

Keywords: Hydrographic basin; Socioeconomics; Family farming.

\section{Resumen}

La agricultura se caracteriza por introducción de pequeños productos familiares en las unidades agrícolas, los cuales establecen culturas, en pequeñas propriedades de tierra, con el uso de tecnología rudimentaria en mano de obra 
familiar, destinando su producción para el autoconsumo. En esta perspectiva, el objetivo fue representar los aspectos ambientales y socioeconómicos de los productores de familias rurales del Médio-parnaíba Piauiense, para que dicha información sirva de base en la toma de decisiones en el ámbito rural. Las encuestas se realizaron en cuatro localidades rurales, por medio de una entrevista sumiestructurada, con un total de 44 entrevistados siendo los datos colectados, analizados por el método de abordaje mixto. Se encontró, que los agricultores entrevistados son mayoritariamente del género masculino (39 individuos), del grupo etario adulto $(54,54 \%)$ y de baja escolaridad $(54,54 \%)$. En términos de ingresos familiares, las ganancias de la agricultura no llegan ni a un salario mínimo para $47,72 \%$ de los participantes. Dentro de los factores que se asocian con el desplazamiento rural hacia las ciudades se destacan; búsqueda por mejorías en las condiciones de vida, escases hídrica y el avance de la agroindustria, sobre todo, en la parte alta del rio. Por otro lado, se infirió que la baja escolaridad se refleja directamente en los ingresos mensuales recibidos por las familias agricultoras, lo que en consecuencia repercute en la infraestructura del sitio de producción, en los mecanismos de uso y manejo de la tierra, así mismo, en los ingresos de los productos obtenidos, denotando, por lo tanto, una fuerte correlación entre las variables socioambientales y el modo de desarrollo agrícola desempeñado por el pequeño productor rural.

Palabras clave: Cuenca hidrográfica; Socioeconomía; Agricultura familiar.

\section{Introdução}

No Brasil, a agricultura familiar é resultante de um processo histórico iniciado com a colonização, no século XVI, sendo influenciada por eventos sociais, políticos e econômicos. Dentro desse cenário, ela se destaca como uma forma de vida de milhares de homens e mulheres que resistem ao longo do tempo, ao processo excludente das políticas governamentais, e que buscam, dentro do mundo capitalista, manter seu espaço em um ambiente cada vez mais competitivo, concorrendo em nível desigual com os empreendimentos que atuam na lógica do agronegócio (Silva \& Jesus, 2010).

De acordo com o Fundo das Nações Unidas para a agricultura e alimentação - FAO e o Instituto Nacional de Colonização e Reforma Agrária - INCRA (1996), a agricultura familiar pode ser definida a partir de três características centrais: gestão da unidade produtiva e os investimentos nela efetuados (que, em geral, são realizados por indivíduos que possuem algum grau de parentesco); pelo trabalho igualitário fornecido pela parentela; e pela propriedade dos meios de produção, que via de regra, pertence à família, ficando a cargo desta a transferência da unidade produtiva.

Do ponto de vista sociológico, os agricultores familiares representam uma forma social específica de trabalho e produção, que se situa em um espaço geográfico definido, cuja atividade implica a interação de um grupo familiar com a terra, outros meios de produção, outras unidades familiares e grupos sociais (Schineider, 2016). Nessa lógica, a agricultura familiar opera como uma unidade de produção, onde terra, trabalho e família estão intimamente relacionados (Carneiro, 1999).

Os agricultores que se inserem na agricultura familiar (pequenos produtores) se caracterizam por possuírem pequenas propriedades e produzirem diferentes culturas, com uso de tecnologias rudimentares e mão de obra familiar, obtendo baixa produtividade em suas atividades agropecuárias, destinando a sua produção para o consumo particular (Peixoto, 1998; Minatel $\&$ Bonganha, 2015). As pessoas que se dedicam a esse tipo de atividade dependem da ampla sanidade do ambiente em que trabalham e buscam com o seu ofício, conquistar o bem-estar da sua família, além de procurar diferentes formas, de participar do mercado de ofertas de alimento (Bittencourt, 2020).

Considerada, portanto, a base para o desenvolvimento de diversos países, a exemplo do Brasil, a agricultura familiar é a responsável por produzir a maior parte dos alimentos que abastecem a mesa dos brasileiros (Zachow \& Plein, 2018). Cerca de $70 \%$ dos mantimentos utilizados na dieta alimentar desses povos, advém dessa atividade, a qual assume destaque para alcançar a soberania alimentar, tendo em vista que $23 \%$ da população padecem pela falta de provimentos (IBGE, 2006).

Em consequência do enfraquecimento de ações que promovam o aumento da sua competitividade e renda, os produtores familiares rurais estão cada vez mais sendo impulsionados a buscarem alternativas para o sustento de suas famílias (Barbosa, et al., 2020). Sendo assim, tem-se observado uma mudança estrutural nas unidades, em que parte dos membros da 
família passa a dedicar-se igualmente às atividades não-agrícolas, praticadas dentro e fora das propriedades rurais, fenômeno conhecido como pluriatividade (Lopes, 2009).

Essa prática vem crescendo gradativamente e possui papel crucial para a economia do país, pois gera emprego e renda para os agricultores, além de exercer papel social fundamental na mitigação do êxodo rural e da desigualdade do campo e da cidade, por estimular o desenvolvimento local e rural (Schneider, 2003; Navarro, 2010; Silva, 2013).

Nesse interim, ao considerar que a compreensão da realidade dos agricultores familiares propicia melhorias nas atividades campesinas e fortalece o seu meio de produção, levantou-se o seguinte questionamento: os aspectos sociais e ambientais refletem o estilo de vida e modelo de produção do pequeno produtor rural? A hipótese norteadora sugere que o perfil social e espacial que se inserem os agricultores familiares rurais repercute na dinâmica de sua atividade produtiva. Nessa perspectiva, objetivou-se representar os aspectos ambientais e socioeconômicos dos produtores familiares rurais do MédioParnaíba piauiense, para que tais informações sirvam de subsídio em tomadas de decisões no âmbito rural.

\section{Metodologia}

A pesquisa foi realizada no alto e baixo curso fluvial da bacia hidrográfica do rio Mulato (BHRM). Ela está inserida na mesorregião do Centro-Norte piauiense e na microrregião do Médio-Parnaíba piauiense (IBGE, 2020). Dentre os municípios que compõem a rede de drenagem, destacam-se Jardim do Mulato (alto curso) e Amarante (baixo curso), sendo que a pesquisa foi conduzida nas localidades rurais de Furnas, Caxingó, Pedra de Amolar e Poço D’anta (Figura 1).

Figura 1 - Localização dos setores territoriais que compuseram o estudo realizado na bacia hidrográfica do rio Mulato, estado do Piauí.
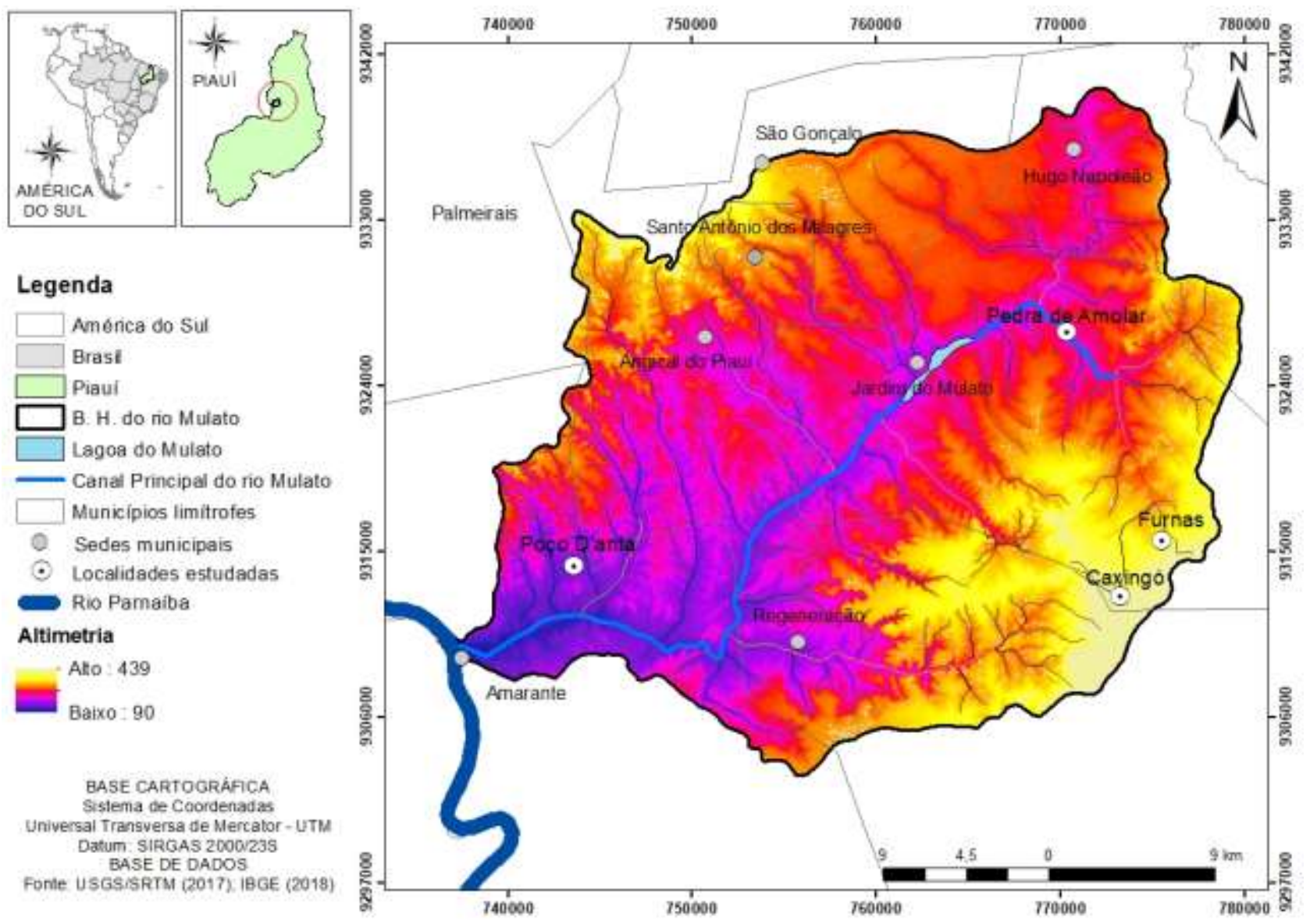

Fonte: USGS/SRTM (2017) e IBGE (2018), elaborado pela autora em 2021. 
De acordo com a estimativa populacional do IBGE (2020), calcula-se que os municípios de Jardim do Mulato e Amarante se somam 22.102 habitantes, sendo 11.492 oriundos da zona rural, cuja fonte de renda provém, prioritariamente, do setor primário (sendo a agropecuária, extração vegetal e silvicultura, os setores que mais empregam), seguido do setor terciário e dos serviços.

Dentre os principais produtos agrícolas de subsistência, destacam-se os cultivos de castanha de caju (Anacardium occidentale L.), banana (Musa paradisiaca L.), manga (Mangifera indica L.), arroz (Oryza sativa L.), feijão (Vigna unguiculata (L.) Walp.) e mandioca (Manihot esculenta Crantz) (IBGE, 2017).

Em relação aos efetivos da pecuária, além da pesca do tambacu/tambatinga (Colossoma macropomum - Cuvier, 1818 x Piaractus brachypomus - Cuvier, 1818), tambaqui (Colossoma macropomum - Cuvier, 1816) e tilápia (Coptodon rendalli Boulenger, 1897), observa-se a criação de galináceos, bovinos, caprinos, ovinos e suínos (IBGE, 2017).

Salienta-se que a pesquisa foi registrada no Sistema Nacional de Gestão do Patrimônio Genético e do Conhecimento Tradicional Associado (SisGen) sob o número de cadastro A7A4B8B e submetida ao Comitê de Ética de Pesquisa da Universidade Federal do Piauí (CEP/UFPI), sendo aprovada e consubstanciada pelo número de parecer 2.100.118, cumprindo, assim, com todas as normativas legais da resolução nº 510/16 do Conselho Nacional de Saúde (CNS).

No tocante aos objetivos da pesquisa, a mesma assumiu caráter descritivo, pois buscou pormenorizar as características da população dos agricultores familiares rurais investigados, cujos dados foram obtidos por meio de roteiros de perguntas previamente elaborados e observação sistemática. Quanto aos procedimentos técnicos, o estudo se qualificou como estudo de campo, visto que procurou compreender de maneira aprofundada, a realidade local (Gil, 2008).

Os dados foram levantados por meio de entrevistas semiestruturadas (Martin, 1995), sendo realizadas com aplicação de formulários, contendo perguntas abertas e fechadas sobre as seguintes variantes socioeconômicas: gênero, idade, estado civil, escolaridade, atividade profissional, tempo de profissão, renda familiar mensal e tempo de moradia na localidade, além das informações ambientais, coletadas durante as visitas in loco.

O público-alvo foi composto por agricultores familiares, com idade igual ou superior a 18 anos, que desempenhassem o ofício anualmente e o exercessem há mais de 10 anos, totalizando 44 informantes. Para definição do universo amostral, utilizou-se o método de abordagem não-probabilística. Desta forma, elegeu-se um membro de cada família auto identificado como produtor familiar responsável pelo núcleo familiar, perfazendo, portanto, todas as residências das localidades (4 domicílios na comunidade Furnas, 2 em Caxingó, 16 no Assentamento Pedra de Amolar e 22 na comunidade Poço D'anta).

No quesito aferição dos dados coletados, os mesmos foram analisados pelo método de abordagem mista (Creswell, 2003), do tipo exploratória e descritiva, sendo a parte quantitativa discutida com base em cálculos percentuais. O programa operacional Excel (2019) serviu igualmente de subsídio para a aquisição dos resultados.

\section{Resultados e Discussão}

\subsection{Perfil Socioeconômico}

A agricultura familiar é marcada, predominantemente, por indivíduos do gênero masculino. Do total de informantes (44), 39 eram desse grupo e apenas cinco do gênero feminino (Tabela 1). O elevado número de pessoas nessa primeira categoria pode ser atribuído ao perfil da atividade, tendo em vista que muitas etapas demandam esforço e resistência física, a exemplo da retirada da cobertura vegetal, limpeza da propriedade, preparação do aceiro, entre outras. Esse resultado corroborou com a pesquisa de Joseph e Rossetto (2021), ao traçar o perfil socioeconômico dos agricultores familiares do Distrito Pantaneiro de Mimoso, em Mato Grosso. Salienta-se, que as mulheres ficam mais restritas às atividades domésticas, embora também atuem nas atividades agrícolas, participando mais ativamente, das etapas de plantio e colheita dos produtos cultivados. O oposto foi observado pelo estudo de Barbosa et al. (2020), onde 70\% da população amostrada constituiu-se de 
mulheres exercendo predominantemente, a atividade profissional da agricultura familiar. Para os colaboradores desse estudo, tal dado é um reflexo da nova organização familiar nos assentamentos rurais, fato este não observado, no assentamento Pedra de Amolar.

Tabela 1. Dados socioeconômicos das localidades rurais Poço D'anta (Amarante), Furnas (Jardim do Mulato), Caxingó (Jardim do Mulato) e Pedra de Amolar (Jardim do Mulato), estado do Piauí. Convenções: M- Masculino; F- Feminino; SESem Escolaridade; EFI- Ensino Fundamental Incompleto; EFC- Ensino Fundamental Completo; EMI- Ensino Médio Incompleto; EMC- Ensino Médio Completo; ES- Ensino Superior; S- Solteiro, C- Casado; D- Divorciado; V- Viúvo; UEUnião Estável; SL- Salário Mínimo; P- Própria; AR- Arrendada.

\begin{tabular}{|c|c|c|c|c|c|c|c|c|c|}
\hline \multirow[t]{2}{*}{ Áreas de estudo } & \multicolumn{9}{|c|}{ Dados socioeconômicos } \\
\hline & Gênero & Idade & Escolaridade & $\begin{array}{c}\text { Estado } \\
\text { civil }\end{array}$ & Profissão & Renda & $\begin{array}{l}\text { Tempo de } \\
\text { profissão }\end{array}$ & Propriedade & $\begin{array}{c}\text { Tempo de } \\
\text { moradia }\end{array}$ \\
\hline \multirow{22}{*}{$\begin{array}{l}\text { Poço D'anta } \\
\text { (Amarante) }\end{array}$} & $\mathrm{M}$ & 67 & EFI & $\mathrm{C}$ & Lavrador & $1 \mathrm{SM}$ & 57 & $\mathrm{AR}$ & 57 \\
\hline & $\mathrm{M}$ & 50 & EFC & $\mathrm{C}$ & Lavrador & $<1 \mathrm{SM}$ & 35 & $\mathrm{P}$ & 50 \\
\hline & $\mathrm{M}$ & 64 & EFI & $\mathrm{C}$ & Lavrador & $1 \mathrm{SM}$ & 54 & AR & 20 \\
\hline & $\mathrm{M}$ & 69 & EFC & $\mathrm{C}$ & Lavrador & $2 \mathrm{SM}$ & 59 & $\mathrm{P}$ & 14 \\
\hline & $\mathrm{F}$ & 75 & SE & $\mathrm{C}$ & Lavrador & $1 \mathrm{SM}$ & 65 & $P$ & 45 \\
\hline & $\mathrm{M}$ & 52 & EFI & $\mathrm{C}$ & Lavrador & $<1 \mathrm{SM}$ & 40 & $\mathrm{AR}$ & 52 \\
\hline & $\mathrm{M}$ & 70 & SE & $\mathrm{C}$ & Lavrador & $1 \mathrm{SM}$ & 60 & $\mathrm{AR}$ & 40 \\
\hline & $\mathrm{M}$ & 70 & SE & $\mathrm{C}$ & Lavrador & $1 \mathrm{SM}$ & 60 & $\mathrm{AR}$ & 50 \\
\hline & $\mathrm{M}$ & 59 & EFI & $\mathrm{C}$ & Lavrador & $1 \mathrm{SM}$ & 21 & AR & 59 \\
\hline & $\mathrm{F}$ & 60 & EFI & $\mathrm{V}$ & Lavrador & $2 \mathrm{SM}$ & 60 & $\mathrm{P}$ & 40 \\
\hline & $\mathrm{M}$ & 68 & EFI & $\mathrm{C}$ & Lavrador & $1 \mathrm{SM}$ & 61 & $\mathrm{P}$ & 68 \\
\hline & M & 70 & $\mathrm{SE}$ & $\mathrm{C}$ & Lavrador & $1 \mathrm{SM}$ & 60 & $P$ & 70 \\
\hline & $\mathrm{M}$ & 74 & SE & $\mathrm{C}$ & Lavrador & $1 \mathrm{SM}$ & 64 & $\mathrm{AR}$ & 50 \\
\hline & $\mathrm{M}$ & 63 & SE & $\mathrm{V}$ & Lavrador & $1 \mathrm{SM}$ & 56 & $\mathrm{AR}$ & 63 \\
\hline & $\mathrm{M}$ & 38 & EFI & $\mathrm{C}$ & Lavrador & $<1 \mathrm{SM}$ & 30 & AR & 10 \\
\hline & $\mathrm{M}$ & 69 & EFC & $\mathrm{V}$ & Lavrador & $1 \mathrm{SM}$ & 63 & $\mathrm{P}$ & 67 \\
\hline & $\mathrm{F}$ & 70 & EFI & $\mathrm{V}$ & Lavrador & $2 \mathrm{SM}$ & 20 & $\mathrm{P}$ & 40 \\
\hline & $\mathrm{M}$ & 58 & EFI & $\mathrm{UE}$ & Lavrador & $2 \mathrm{SM}$ & 10 & AR & 37 \\
\hline & $\mathrm{M}$ & 51 & EFI & $\mathrm{S}$ & Lavrador & $<1 \mathrm{SM}$ & 41 & AR & 51 \\
\hline & $\mathrm{M}$ & 46 & EFI & $\mathrm{C}$ & Lavrador & $<1 \mathrm{SM}$ & 40 & $\mathrm{AR}$ & 46 \\
\hline & $\mathrm{M}$ & 39 & EFI & UE & Lavrador & $<1 \mathrm{SM}$ & 30 & AR & 17 \\
\hline & $\mathrm{M}$ & 48 & EFI & $\mathrm{C}$ & Lavrador & $1 \mathrm{SM}$ & 36 & AR & 26 \\
\hline \multirow{4}{*}{$\begin{array}{l}\text { Furnas (Jardim } \\
\text { do Mulato) }\end{array}$} & $\mathrm{M}$ & 57 & EFI & $\mathrm{C}$ & Lavrador & $<1 \mathrm{SM}$ & 45 & $\mathrm{P}$ & 57 \\
\hline & $\mathrm{M}$ & 67 & EFI & $\mathrm{C}$ & Lavrador & $1 \mathrm{SM}$ & 55 & $P$ & 67 \\
\hline & $\mathrm{F}$ & 56 & EFI & $\mathrm{V}$ & Lavrador & $<1 \mathrm{SM}$ & 41 & $\mathrm{P}$ & 15 \\
\hline & $\mathrm{M}$ & 69 & EMC & $\mathrm{C}$ & Lavrador & $1 \mathrm{SM}$ & 57 & $P$ & 69 \\
\hline \multirow{2}{*}{$\begin{array}{l}\text { Caxingó } \\
\text { (Jardim do } \\
\text { Mulato) }\end{array}$} & $\mathrm{M}$ & 34 & EMI & $\mathrm{C}$ & Lavrador & $<1 \mathrm{SM}$ & 24 & $\mathrm{P}$ & 34 \\
\hline & $\mathrm{M}$ & 74 & EFI & $\mathrm{C}$ & Lavrador & $1 \mathrm{SM}$ & 64 & $\mathrm{P}$ & 74 \\
\hline \multirow{16}{*}{$\begin{array}{c}\text { Pedra de } \\
\text { Amolar (Jardim } \\
\text { do Mulato) }\end{array}$} & $\mathrm{M}$ & 38 & EFI & $\mathrm{C}$ & Lavrador & $<1 \mathrm{SM}$ & 23 & $\mathrm{P}$ & 18 \\
\hline & $\mathrm{M}$ & 29 & EFC & UE & Lavrador & $<1 \mathrm{SM}$ & 17 & $\mathrm{AR}$ & 16 \\
\hline & M & 46 & EFC & $\mathrm{V}$ & Lavrador & $<1 \mathrm{SM}$ & 34 & $\mathrm{P}$ & 18 \\
\hline & $\mathrm{M}$ & 71 & SE & $\mathrm{C}$ & Lavrador & $1 \mathrm{SM}$ & 50 & $\mathrm{P}$ & 18 \\
\hline & $\mathrm{M}$ & 66 & EFI & $\mathrm{V}$ & Lavrador & $1 \mathrm{SM}$ & 62 & $\mathrm{AR}$ & 16 \\
\hline & $\mathrm{M}$ & 52 & ES & $\mathrm{C}$ & Lavrador & $<1 \mathrm{SM}$ & 22 & $P$ & 18 \\
\hline & $\mathrm{F}$ & 60 & EFI & V & Lavrador & $<1 \mathrm{SM}$ & 51 & $\mathrm{P}$ & 18 \\
\hline & $\mathrm{M}$ & 58 & EMI & $\mathrm{C}$ & Lavrador & $1 \mathrm{SM}$ & 40 & AR & 18 \\
\hline & $\mathrm{M}$ & 65 & SE & $\mathrm{C}$ & Lavrador & $1 \mathrm{SM}$ & 55 & $\mathrm{P}$ & 16 \\
\hline & $\mathrm{M}$ & 52 & SE & $\mathrm{C}$ & Lavrador & $<1 \mathrm{SM}$ & 37 & $\mathrm{P}$ & 18 \\
\hline & $\mathrm{M}$ & 35 & EFI & $\mathrm{C}$ & Lavrador & $<1 \mathrm{SM}$ & 14 & $\mathrm{P}$ & 18 \\
\hline & $\mathrm{M}$ & 47 & EFI & $\mathrm{C}$ & Lavrador & $<1 \mathrm{SM}$ & 39 & $\mathrm{P}$ & 18 \\
\hline & $\mathrm{M}$ & 59 & SE & $\mathrm{V}$ & Lavrador & $<1 \mathrm{SM}$ & 47 & $\mathrm{P}$ & 18 \\
\hline & $\mathrm{M}$ & 58 & EFI & $\mathrm{C}$ & Lavrador & $<1 \mathrm{SM}$ & 46 & $\mathrm{P}$ & 18 \\
\hline & $\mathrm{M}$ & 49 & SE & $\mathrm{C}$ & Lavrador & $<1 \mathrm{SM}$ & 20 & $P$ & 18 \\
\hline & $\mathrm{M}$ & 55 & EFI & $\mathrm{C}$ & Lavrador & $<1 \mathrm{SM}$ & 43 & AR & 18 \\
\hline
\end{tabular}

Fonte: Pesquisa direta (2021). 
De acordo com o que preconiza o Instituto Brasileiro de Geografia e Estatística (IBGE, 2010), grande parte dos agricultores $(54,54 \%)$ integraram a faixa etária adulta (compreendida de 25 a 59 anos), inserindo-se, portanto, no grupo da população economicamente ativa. Os demais, incluíram-se na faixa etária idosa (60 anos ou mais), não sendo observada a participação de jovens (18 a 24 anos) no desempenho do ofício (Tabela 1). Esses dados corroboraram com a pesquisa de Pinto Filho, Gonçalves e Lunes (2019), ao apresentar a caracterização socioeconômica e ambiental das comunidades rurais da chapada do Apodi, no estado do Rio Grande do Norte. Salienta-se, que a ausência dessa parcela da população, pode estar relacionada a atuação em outros serviços remuneratórios. Para Wanderley (2013) e Valadares et al. (2016), o baixo contingente de agricultores familiares jovens no semiárido, relacionam-se as limitações fundiárias das pequenas propriedades, que não tem suporte para ampliação da exploração de recursos naturais pelas novas gerações; a falta de oportunidades de trabalho e de melhoria de renda no campo; além das dificuldades de acesso aos serviços básicos e de infraestrutura.

Segundo Godoy e Wizniewsky (2013) é possível visualizar no meio rural, dois fenômenos: o envelhecimento da população e o êxodo rural de jovens para os grandes centros urbanos. Para Souza (2012), a saída dos jovens do campo para a cidade está atrelada à ocupação em outras atividades, como estudar e/ou trabalhar em outros setores, externos ao meio rural, o que se torna um fator preocupante do ponto de vista da reprodução social, uma vez que, a não participação dos adolescentes, desfavorecem a continuidade das técnicas utilizadas no campo, assim como a sucessão familiar. Por outro lado, o desempenho em outras atribuições contribui para a melhoria das condições de vida dos pequenos produtores familiares, posição tão almejada por esse público.

De modo geral, Silva et al. (2020) destacam, que tais fatores expressam não apenas as heranças do abandono e da negação do espaço rural, mas também a escassez de políticas públicas que assegurem a qualidade de vida e o pleno desenvolvimento das capacidades dos jovens no campo. Diante disso, investir em capacitações técnicas, por meio de cursos de pequena duração, que oriente suas práticas agrícolas e por consequência, potencialize os seus meios de produção, poderia ser uma das estratégias adotadas, com vistas à manutenção das novas gerações, no campesinato.

No quesito escolaridade (Tabela 1), prevaleceram agricultores que estudaram o ensino fundamental de forma incompleta (54,54\%), seguido daqueles que não possuem nenhuma escolaridade (25\%). A dificuldade em concluir os estudos podem estar associados à ausência de escolas nas próprias localidades, forçando as pessoas a se deslocarem para regiões vizinhas ou para a zona urbana das cidades; ausência de oportunidades, levando os indivíduos a seguirem a mesma trajetória de vida daqueles que não conseguiram alcança-los; emergente necessidade em ajudar os familiares no campo; e não menos importante, o desinteresse em prossegui-los. Dados similares foram evidenciados na pesquisa de Lima, Melo e Barbosa (2021), ao investigarem as comunidades Jenipapo, Olho D'água do Raposo e Usina Velha, no estado do Maranhão.

De acordo com o Instituto de Pesquisa Econômica Aplicada (IPEA, 2010), a baixa qualificação das pessoas no campo, podem implicar não só em danos econômicos e ambientais, como também na saúde do agricultor. Nesse sentido, Medina (2018) ressalta a importância do acesso à educação, por parte dos pequenos produtores rurais, uma vez que essa ferramenta contribui tanto para o desenvolvimento próspero das unidades de produção (tendo em vista que o agricultor pode se qualificar), quanto para ajudá-los a enfrentar os crescentes desafios da sociedade.

Para Nunes et al. (2020), a combinação de uma infraestrutura de produção precária e a baixa escolaridade da população rural, tem contribuído para a reprodução de um círculo vicioso de fragilidade socioeconômica, caracterizada por baixos rendimentos e baixo nível tecnológico.

Relativo ao estado civil dos participantes, a maioria $(70,45 \%)$ declararam serem casados (Tabela 1). O resultado aponta para a importância da constituição familiar no meio rural, sobretudo no tocante à prática da agricultura itinerante (do tipo roça), que em geral, envolve integrantes do mesmo núcleo familiar. Esse dado corroborou com a pesquisa de Barbosa et al. (2020), ao traçarem o perfil socioeconômico e ambiental de agricultores familiares assentados no município de Pio IX, no 
estado do Piauí. Silva (2021) argumenta, que a centralidade do papel da família na organização da produção e na constituição do modo de vida, associado ao patrimônio fundiário, são elementos comuns dessa categoria social.

Em relação a ocupação profissional (Tabela 1), todos (100\%) afirmaram trabalhar no contexto da agricultura familiar (sendo autodenominados lavradores), exercendo o seu ofício em terras próprias (compradas ou herdadas), mas também de terceiros (arrendadas). Aqueles que desempenham sua atividade em terras arrendadas $(40,90 \%)$, percebem valor monetário por diária ( $\mathrm{R} \$ 50,00$ a 60,00 reais o dia trabalhado) ou fazem ônus à parcela ( $2 / 4$ por tarefa) dos produtos que foram produzidos (câmbio). Em geral, o produto recebido em troca do serviço prestado consiste no arroz (Oryza sativa L.). Dados correspondentes foram verificados por Macêdo et al. (2020), ao abordarem os elementos sociais, econômicos e culturais das comunidades Costaneira e Tronco, no estado do Piauí. Vale ressaltar, que a unidade de medida "tarefa" citada pelos participantes, corresponde a 25 quadras de 2 metros, de acordo com os mesmos.

Os principais produtos agrícolas cultivados nas propriedades são o arroz (Oryza sativa L.), feijão (Vigna unguiculata (L.) Walp.), milho (Zea mays L.) e mandioca (Manihot esculenta Crantz), sendo empregada mão de obra essencialmente familiar e técnicas de produção arcaicas, de baixo impacto ambiental e sem aditivos químicos. Segundo Melo, Silva e Melo (2017), essa característica é esperada, pois constitui traço fundamental desse tipo de sistema de produção. Destaca-se ainda, que além dos produtos oriundos de lavouras temporárias e permanentes, a criação de animais $(e$. g. bovinos, caprinos, suínos e galináceos) consiste em outra atividade desempenhada por parte dos lavradores, sendo essa realizada em menor expressividade.

Os proventos oriundos da agricultura não chegam a um salário mínimo ( $\mathrm{R} \$ 1.100,00$ ), para 47,72\% dos participantes (Tabela 1). Aos que declararam receber um ou mais salários ou estão na posição de aposentados e/ou recebem pensão, ou ainda complementam sua renda por meio de atividades secundárias (e.g. servente de pedreiro). Os estudos de Alves et al. (2016) indicam, que em média, o valor bruto de produção mensal por propriedade familiar é de 0,46 salário mínimo, o que coloca grande parte dos produtores em situação de extrema pobreza. Assim, as famílias em situação de vulnerabilidade socioeconômica também recorrem aos benefícios sociais do Governo Federal, as quais fazem dessa benesse, a sua principal fonte de renda fixa. Informações correspondentes foram verificadas por Sousa et al. (2020), ao traçarem o perfil socioeconômico de produtores de farinha de mandioca na Vila de Igarapé- Açu, Capitão Poço, no estado do Pará.

Cabe destacar, que a agricultura familiar é um tipo de serviço que se inicia desde muito cedo na vida dos trabalhadores (em geral, a partir de 10 anos de idade), sendo suas práticas passadas entre as gerações, o que os levam a possuírem muito tempo e experiência na profissão. De acordo com Sousa et al. (2020), apesar dos produtores familiares não possuírem qualificação profissional, o etnoconhecimento constitui fonte de qualificação empírica, visto que os saberes transmitidos aos descendentes é a principal ferramenta de conhecimento desses povos.

No quesito tempo de moradia nas localidades pesquisadas (Tabela 1), os partícipes relataram residir entre 15 a 74 anos in loco, embora todos sejam nascidos e/ou criados nos seus respectivos municípios de origem. Do ponto de vista técnicooperacional, esse dado se torna relevante por promover a garantia da manutenção do sistema de produção tradicional/local, visto que não houve relatos de pessoas oriundas de outras regiões, que pudessem estar introduzindo conhecimentos baseados em outros modelos de produção. Para Carvalho e Rodrigues (2015), o período de residência é um fator preponderante em análises locais, por oferecer conhecimento sobre a situação da população, além de poder inspirar a continuidade da configuração evidenciada na íntima relação dos indivíduos que ali residem e o seu ambiente físico.

\subsection{O contexto das localidades}

A comunidade rural Poço D’anta (Figura 2), localizada no município de Amarante, era conhecida no início do seu povoamento, como Poço das Antas. Essa nomenclatura foi sofrendo variações com o tempo, até se chegar no nome como ela é 
reconhecida hoje. Ela dista cerca de $11 \mathrm{~km}$ da sede urbana e apresenta 22 famílias domiciliadas (ano base 2021), dado este confirmado no local, durante as visitas realizadas na área.

Figura 2. Comunidade rural Poço D'anta, situada no município de Amarante, estado do Piauí. A- Panorama da comunidade Poço D'anta. B- Caixa d'água que abastece a comunidade Poço D'anta. C- Posto de saúde da comunidade Poço D'anta. DIgreja católica da comunidade Poço D’anta.

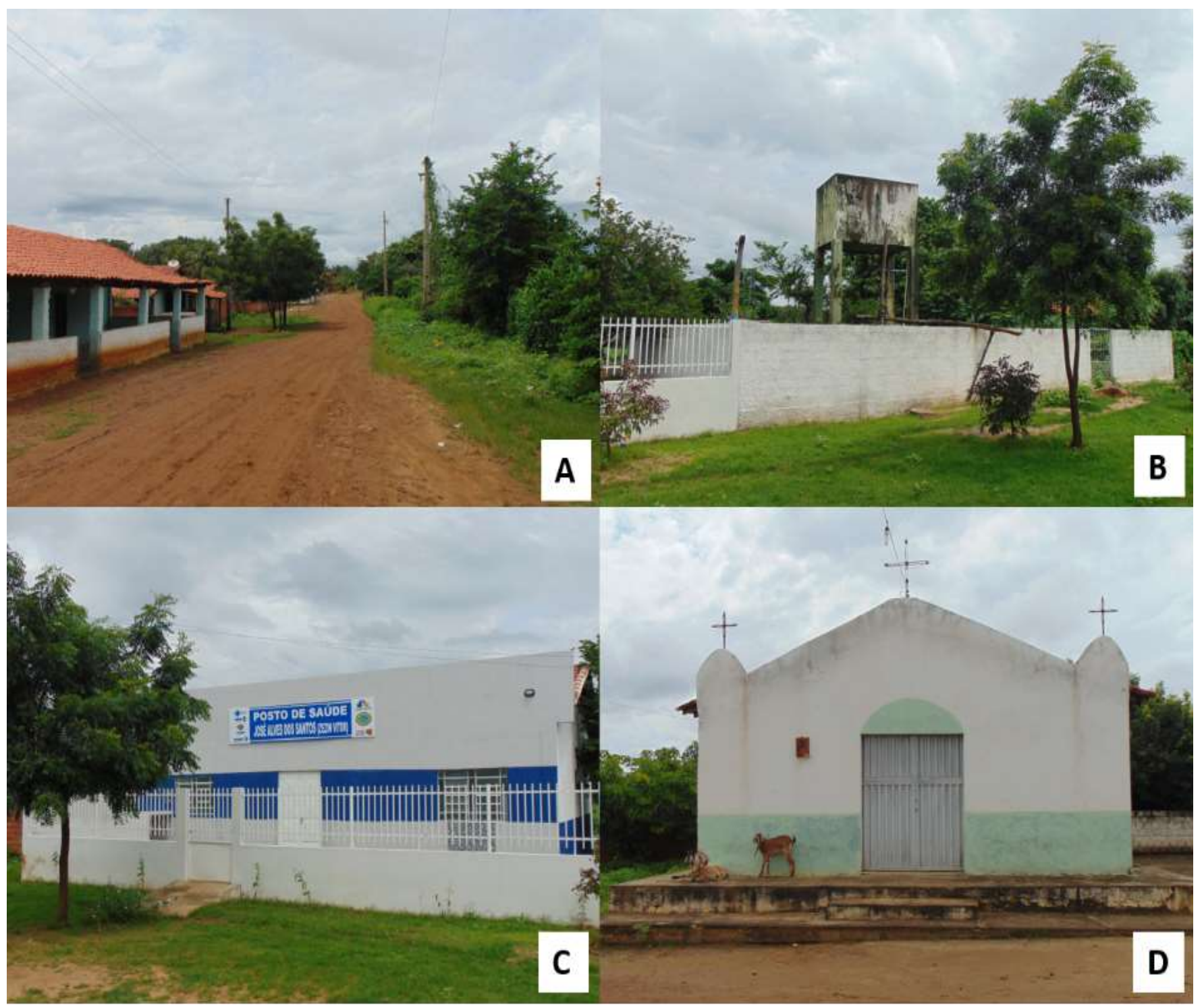

Fonte: Autora em fevereiro de 2020.

Relativo aos aspectos infraestruturais, a comunidade dispõe de poço tubular (Figura 2B), no qual é responsável pelo seu abastecimento hídrico; rede de energia elétrica; de telefonia; posto de saúde (Figura 2C), local em que se realizam atendimentos médicos básicos especializados; e igreja católica (Figura 2D), onde se realiza os festejos de Nossa Senhora de Fátima, no mês de maio. Ela não possui escola ativa, logo a população precisa se deslocar para a sede urbana do referido município, em transporte público, para ter acesso ao ensino formal. Também não dispõe de rede de esgoto e coleta de lixo, logo os efluentes líquidos residuais são despejados nos quintais das residências e os resíduos sólidos são queimados. Este dado foi igualmente observado por Batista et al. (2016), ao estudarem a comunidade rural Novo Nilo, município de União, estado do Piauí. 
A comunidade rural Furnas (Figura 3), situa-se no município de Jardim do Mulato e dista cerca de 21,2 km da sede urbana de Regeneração, tendo em vista que o seu acesso se dá por essa cidade. Ela possuía quatro famílias domiciliadas (ano base 2019). Após o retorno gradual das atividades, ainda no período da pandemia da Covid-19 (ano base 2021), constatou-se que esta passou a contar com apenas três núcleos familiares. Segundo o agente comunitário de saúde, a comunidade era habitada por 39 famílias, no entanto, as mesmas acabaram "cedendo" seu espaço para o avanço do agronegócio (soja - Glycine $\max ($ L.) Merr. e eucalipto - Eucalyptus spp) na região. Os poucos residentes que resistiram no local são aqueles que consideram a questão do pertencimento.

Figura 3. Comunidade rural Furnas, município de Jardim do Mulato, estado do Piauí. A- Estrada de acesso à localidade. BPanorama da comunidade rural Furnas. C- Poço tubular que abastece o local. D- Contato entre uma propriedade privada destinada a agricultura familiar de subsistência (do tipo roça) e o agronegócio.

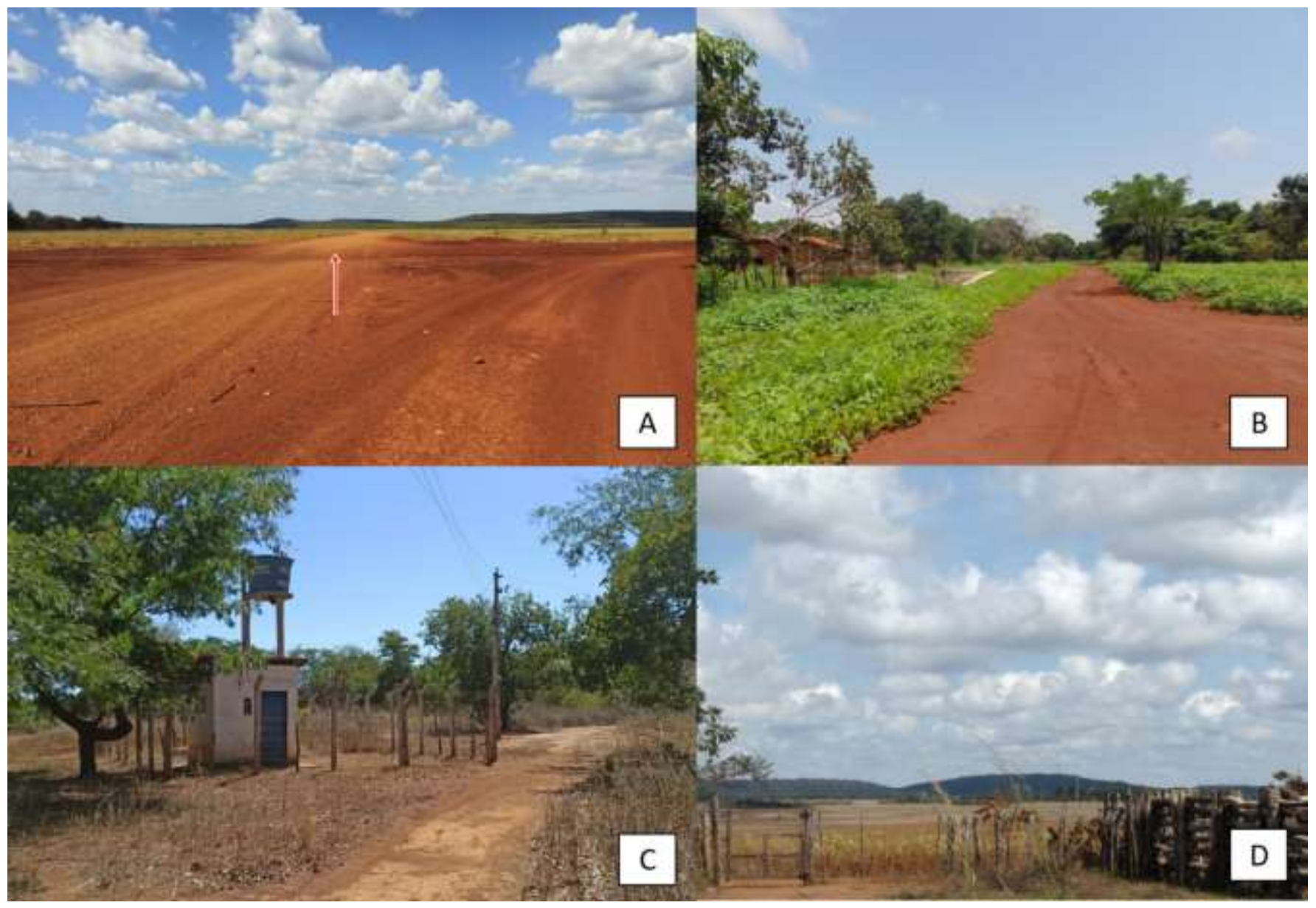

Fonte: Autora em fevereiro de 2019 (3B) e agosto de 2021.

A localidade possui energia elétrica e o abastecimento hídrico se dá por meio de poço tubular (Figura 3B). Posto de saúde e escola estão ausentes, o que leva a população a buscar serviços médicos e educacionais na zona urbana do município. Também não há redes de telefonia na localidade, porém, a população pode obtê-la por meio de antena de acesso particular. Rede de esgoto e coleta seletiva igualmente inexistem na comunidade. Sendo assim, os efluentes residuais líquidos são lançados a céu aberto no quintal da propriedade, enquanto os sólidos são queimados.

A comunidade rural Caxingó (Figura 4) está localizada no município de Jardim do Mulato e dista cerca de $21 \mathrm{~km}$ da sede urbana de Regeneração, visto que o acesso a essa localidade se dá por intermédio desse núcleo urbano. Ela apresenta duas 
famílias domiciliadas (ano base 2021). Por situar-se igualmente no caminho do movimento da fronteira agrícola, os habitantes que permaneceram ali no local, resistiram pelo mesmo motivo da comunidade Furnas.

Figura 4. Comunidade rural Caxingó, município de Jardim do Mulato, estado do Piauí. A- Entroncamento de acesso à localidade Caxingó. B- Panorama da comunidade rural Caxingó.

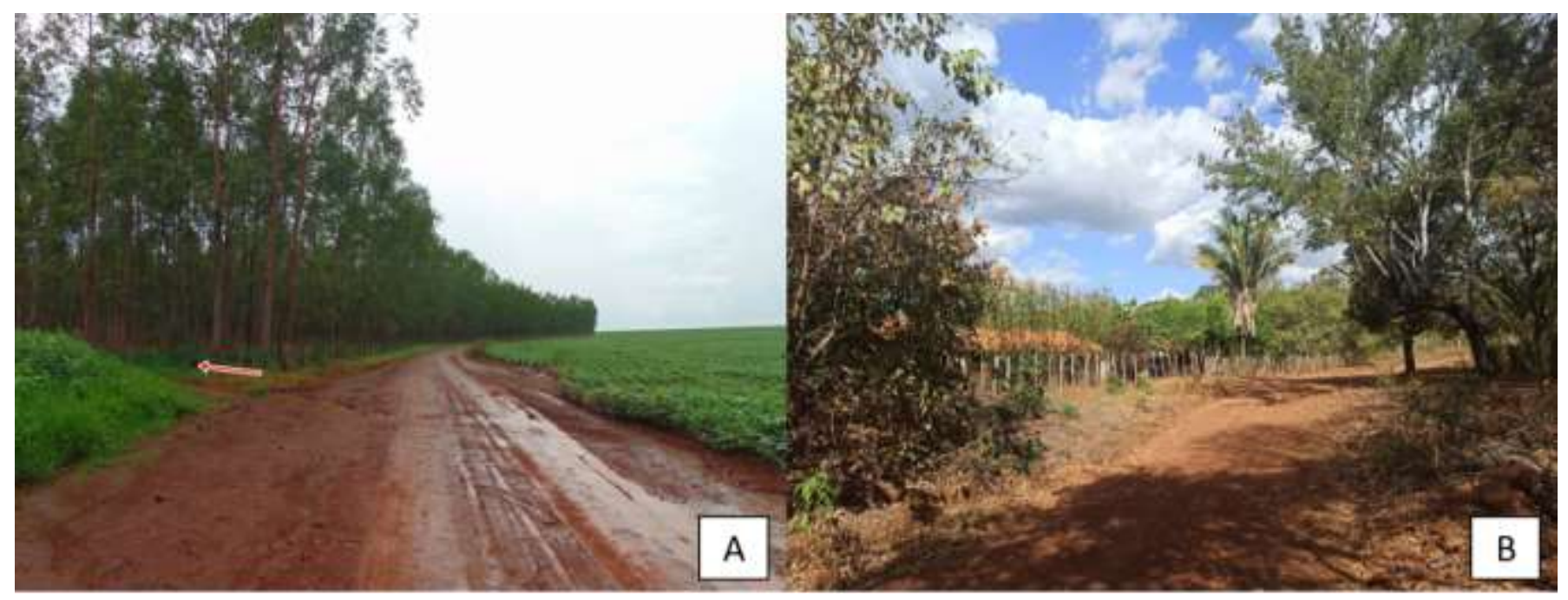

Fonte: Autora em fevereiro de 2019 (4A) e agosto de 2021 (4B).

A comunidade dispõe de energia elétrica. A água chega aos domicílios pelo abastecimento de cisternas ou carros pipa enviados pela empresa do agronegócio instalada na região, tendo em vista a profundidade do lençol freático (mais de 300 metros). Rede de telefonia está presente apenas em alguns pontos da localidade. Escolas e posto de saúde inexistem no local, sendo assim, as famílias precisam se deslocar para a zona urbana municipal para terem acesso a esses serviços. Coleta seletiva de lixo e rede de esgoto inexistem na localidade, o que leva os habitantes a queimarem os resíduos sólidos e a despejarem seus efluentes líquidos no quintal do seu domicílio.

A localidade rural Pedra de Amolar (Figura 5), situa-se no município de Jardim do Mulato e dista cerca de $12 \mathrm{~km}$ da sede municipal. Trata-se de um assentamento criado no ano de 2003, com apoio de um banco brasileiro de economia mista, com participação do Governo Federal, por meio do Crédito Fundiário Rural. As propriedades construídas (18) foram destinadas a habitantes do próprio município que não possuíam habitação e que tinham interesse em financiar/ter sua residência fixa. Todos os lotes de terra estão demarcados, porém, por uma série de burocracias, ainda não foi dado o título oficial aos moradores. $\mathrm{O}$ assentamento dispõe de 18 núcleos familiares (ano base 2021), mas apenas 17 residem efetivamente no local. De todas as casas construídas (18), apenas uma permanece inalterada, em termos estruturais.

O assentamento (Figura 5) dispõe de energia elétrica; posto de saúde (Figura 5B), o qual se encontra desativado, levando os residentes a buscarem serviços médicos na zona urbana municipal; igreja católica (Figura 5C), sendo esta utilizada para reuniões comunitárias e não para fins religiosos; e poço tubular (Figura 5D), responsável pelo abastecimento hídrico da localidade. Não possui rede de telefonia, no entanto, aparelhos telefônicos são utilizados por meio de internet cabeada, por parte daqueles que compraram o acesso a esse serviço. Escolas também inexistem no local. Desse modo, as pessoas precisam se deslocar por meio de transporte público para regiões adjacentes que possuem esse tipo de estabelecimento ou para a sede urbana, em busca do ensino formal. Assim como todas as demais localidades supracitadas, esta não dispõe de rede de esgoto e coleta seletiva de lixo. Logo, os efluentes líquidos e sólidos são lançados e/ou queimados na própria propriedade.

Vale ressaltar, que o acesso às localidades pesquisadas se dá por estradas carroçais (sem pavimentação), o que confere certa dificuldade em acessá-las, principalmente no inverno (verão chuvoso), período em que ocorre alagamentos, formações de 
crateras e rupturas, em determinados trechos da via. Após o verão chuvoso é comum os trajetos mais assolados pela força da água, serem recuperados, por meio de máquinas (tratores).

Figura 5- Assentamento Pedra de Amolar, localizado no município de Jardim do Mulato, estado do Piauí. A- Panorama da localidade Pedra de Amolar. B- Posto de saúde do assentamento Pedra de Amolar. C- Igreja Católica do assentamento Pedra de Amolar. D- Poço Tubular que abastece o assentamento Pedra de Amolar.

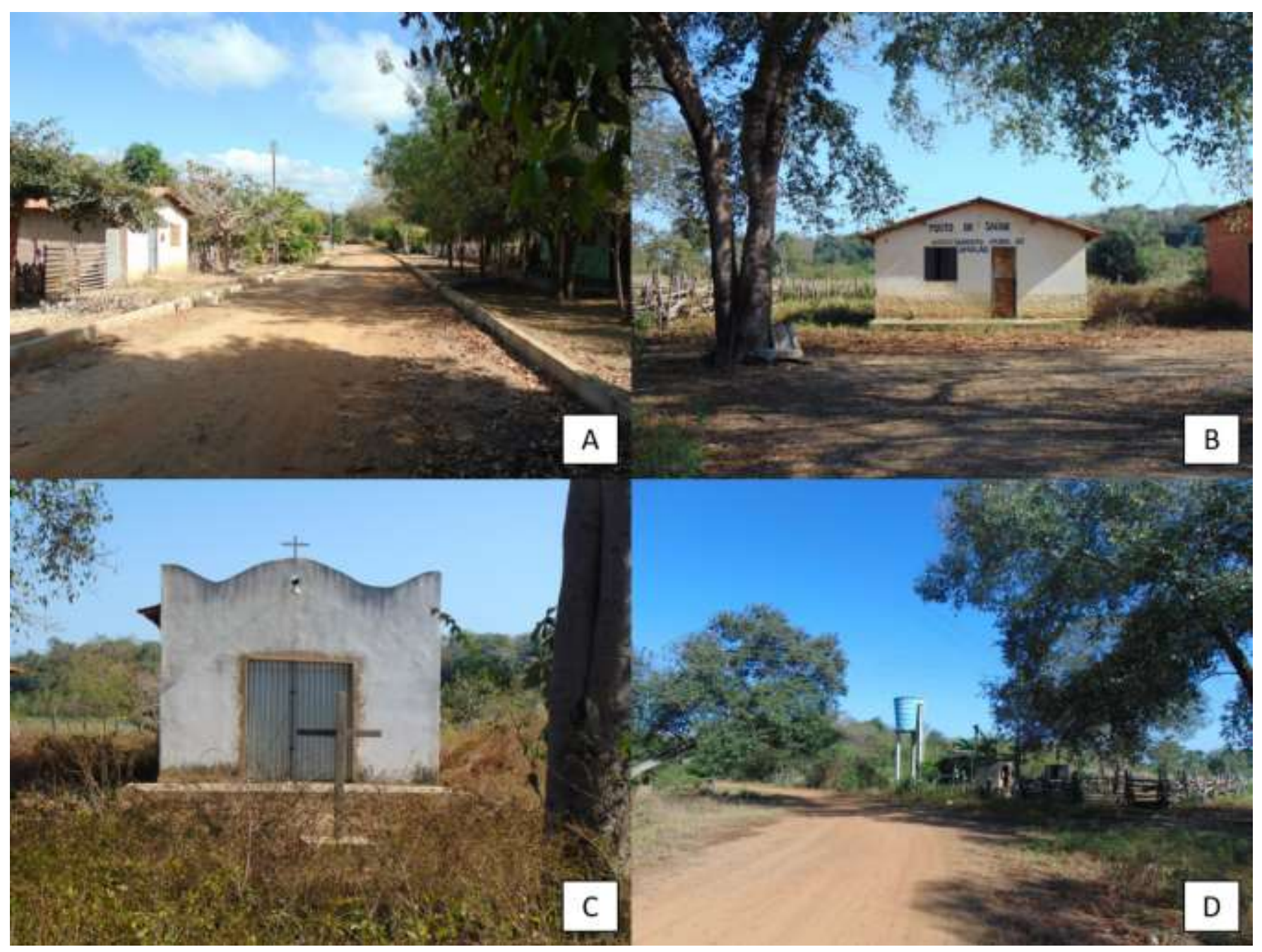

Fonte: Autora em agosto de 2021.

Destaca-se, que a deficiência hídrica associado ao agronegócio de grãos e monocultivos no alto curso da BHRM, tem sido o principal agravante na manutenção das famílias na região. Tais fatores tem contribuído, do mesmo modo, para que a população saia do campo e migre para a cidade, fatos estes não observados no baixo curso fluvial. Além da profundidade do lençol freático, a escassez de água também tem sido atribuída ao avanço da fronteira agrícola na região. Ao assentar-se no sistema de Plantation, o agronegócio coloca em risco a biodiversidade e a saúde humana, uma vez que ocasiona diversas consequências sociais, econômicas e ambientais (Oliveira, 2006).

Diferentemente da agricultura familiar, que se caracteriza pela produção de alimentos, necessários e fundamentais à existência da humanidade, de forma mais sustentável, o agronegócio visa a produção de commodities (mercadorias), para o mercado mundial (Oliveira, 2006). Ele se distingue do modo camponês, pelas práticas da acumulação, monocultura, trabalho assalariado e produção em larga escala, deixando de lado a biodiversidade e a agricultura familiar (Welch \& Fernandes, 2008). 
Dentre os impactos provocados por esse tipo de sistema de produção na região, os pequenos agricultores destacaram: a venda da propriedade por valores irrisórios, aumento de casos de roubo/assaltos na região, perda do vínculo afetivo com os antigos residentes, uso de máquinas, emprego de mão de obra com baixa remuneração, aumento da temperatura local, redução da disponibilidade hídrica, alteração na dinâmica do vento (em detrimento da retirada da vegetação) e envenenamento das abelhas, causado pelo uso expressivo de insumos químicos (e.g. agrotóxicos). Para os informantes da pesquisa, tais efeitos têm aumentado consideravelmente, com a chegada do agronegócio e sua consequente movimentação.

Para Silva (2021), as repercussões do processo de ocupação empresarial do cerrado piauiense são questionadas por estudiosos do desenvolvimento agrário. Em vista disso, Silva (2016) constatou, as mudanças socioespaciais acarretadas pelo agronegócio, no município de Uruçuí/PI, à medida em que se tem avançado sob as terras de uso comum, suscitando incertezas sobre o futuro da agricultura familiar, a sustentabilidade dos recursos naturais e a trajetória dos modos de vida rurais e das identidades territoriais. Em face disso, é notória a congruência dos resultados desse autor com os observados nesse estudo, uma vez que, esse tipo de modelo de desenvolvimento dominante, tem causado a expropriação dos agricultores familiares rurais dos seus locais de origem, "forçando-os" a abandonarem suas práticas agrícolas tradicionais, ambientalmente mais sustentáveis.

\section{Conclusão}

Diante das informações apresentadas, depreende-se que a baixa escolarização reflete diretamente na renda mensal percebida pelos agricultores familiares rurais, que por consequência repercute na infraestrutura do seu local de produção, nos mecanismos de uso e manejo da terra, bem como nos rendimentos dos produtos obtidos, denotando, portanto, forte correlação entre as variáveis socioambientais e o modo de desenvolvimento agrícola desempenhado pelo pequeno produtor rural.

A agricultura familiar rural ainda é notadamente marcada pelo uso de ferramentas rudimentares, emprego de mão de obra familiar e produção em pequena escala (voltada essencialmente, para o autoconsumo). No entanto, com o avanço do agronegócio na região, sobretudo alto curso fluvial, pode ser que num futuro não muito longínquo, as práticas tradicionais/locais sejam substituídas pelos modelos de produção dominante, o que pode levar a total alteração da dinâmica socioprodutiva local.

Mesmo diante de todos os desafios impostos pelo meio rural, os agricultores familiares rurais continuam resistindo às mudanças socioespaciais oriundas do movimento da fronteira agrícola, pois continuam desenvolvendo atividades agrícolas de base sustentável, meio pelas quais garantem a sua subsistência e de seus núcleos familiares. Nesse viés, recomenda-se a inserção de debates sociais e ambientais nas regiões alcançadas pelo agronegócio, que visem a mitigação dos conflitos resultantes desse modelo de desenvolvimento, para que dessa forma, a sociedade reconheça a importância de ambos os sistemas de produção.

\section{Agradecimentos}

À Universidade Federal do Piauí (UFPI), à Coordenação de Aperfeiçoamento de Pessoal de Nível Superior (CAPES) e as localidades rurais pesquisadas.

\section{Referências}

Alves, E., Souza, G. S., \& Santana, C. A. M. (2016). Pobreza e sustentabilidade. Revista de Política Agrícola, (4), 63-81.

Barbosa, T. C. S. B., Freitas, W. N., Dias, I. M., Brito, J. A. L., Costa, N. M. G. B., \& Sousa, M. F. S. (2020). Perfil socioeconômico e ambiental de agricultores familiares em um assentamento rural no estado do Piauí. Brazilian Journal of Development, 6(6), 41856-41865.

Batista, W. F. M., Santos, K. P. P., Figueiredo, L. S. \& Barros, R. F. M. (2016). Sociedade e cultura: o caso da comunidade rural Novo Nilo. Espacios, 37(3), 1-12. 
Bittencourt, D. M. C. (2020). Estratégias para a agricultura familiar: visão de futuro rumo à inovação. Embrapa.

Carneiro, M. J. (1999). Agricultores familiares e pluriatividade: tipologias e políticas. In: Costa, L.F.C, Moreira, R.J. \& Bruno, R. (Org.). Mundo rural e tempo presente (pp. 325- 344). Rio de Janeiro: Mauad.

Carvalho, A. P. \& Rodrigues, M. A. N. (2015). Percepção ambiental de moradores no entorno do açude Soledade no estado da Paraíba. Revista Eletrônica em Gestão, Educação e Tecnologia Ambiental, 19(3), 25-35.

Creswell, J. W. (2007). Projeto de pesquisa: métodos qualitativo, quantitativo e misto. Artmed.

FAO/INCRA (1996). Perfil da agricultura familiar no Brasil: dossiê estatístico. FAO/INCRA.

Gil, A. C. (2008). Como elaborar projetos de pesquisa. Atlas.

Godoy, C. M. T. \& Wizniewsky, J. G. (2013). O papel da pluriatividade no fortalecimento da agricultura familiar do município de Santa Rosa/RS. Desafio Online, 1(3), 1-16.

IBGE. Instituto Brasileiro de Geografia e Estatística. (2006). Censo agropecuário 2006: agricultura familiar, primeiros resultados. https://biblioteca.ibge.gov.br/index.php/biblioteca-catalogo?id=750\&view=detalhes

IBGE. Instituto Brasileiro de Geografia e Estatística. (2017). Censo Agropecuário. https://www.ibge.gov.br/estatisticas/economicas/agricultura-epecuaria/21814-2017-censo-agropecuario.html?=\&t=o-que-e

IBGE. Instituto Brasileiro de Geografia e Estatística. (2020). Cidades. https://cidades.ibge.gov.br/

IPEA. Instituto de Pesquisa Econômica Aplicada. (2010). Publicações. https://www.ipea.gov.br/portal/index.php?option=com_ alphacontent $\&$ section=31\&category=271\&Itemid=357\&limitstart=20

Joseph, L. A. \& Rossetto, O. C. (2021). Perfil socioeconômico dos agricultores familiares do Distrito pantaneiro de Mimoso, município de Santo Antônio de Leverger-MT. Revista Eletrônica da Associação dos Geógrafos Brasileiros Seção Três Lagoas, 1(33), 82-105.

Lima, L. B., Melo, A. F. \& Barbosa, D. R. S (2021). O território quilombola, em comunidades no interior do nordeste do Brasil: caracterização socioeconômica e estrutural preliminar. Research, Society and Development, 10(13), 1-12.

Lopes, E. S. A. \& Costa, J. E. (2009). Territórios rurais e agricultura familiar no Nordeste. EDUFS.

Macêdo, E. M., Batista, M. L. P., Figueiredo, L. S. \& Barros, R. F. M. (2020). Elementos sociais, econômicos e culturais constitutivos de uma comunidade quilombola no nordeste do Brasil. Research, Society and Development, 9(11), 1-28.

Martin, G. J. (1995). Ethnobotany: a conservation manual. Chapman \& Hall.

Medina, G. (2018). Agricultura familiar em Goiás: lições para o assessoramento técnico. UFG.

Melo, S. A. B. X., Silva, F. S. \& Melo, A. X. (2017). Aspectos socioeconômico dos agricultores familiares extrativistas do Cumbaru no município de Poconé Pantanal Mato-Grossense. Revista Ibero-Americana de Ciências Ambientais, 8(1), 62-73.

Minatel, J. F. \& Bonganha, C. A. (2015). Agronegócios: a importância do cooperativismo e da agricultura familiar. Empreendedorismo, Gestão e Negócios, 4(4), 247-259.

Navarro, Z. (2010). A agricultura familiar no Brasil: entre a política e as transformações da vida econômica. In: Gasques, J.G., Vieira Filho, J.E. \& Navarro, Z. (Org.). A agricultura brasileira: desempenho, desafios e perspectivas (pp. 185-209). Brasília: IPEA.

Oliveira, A. U. (2006). A Amazônia e a nova geografia da produção da soja. Terra livre, 1(26), 13-43.

Peixoto, S. E. (1998). A pesquisa e a agricultura familiar. Revista Bahia Agrícola, 2(3), 50-56.

Pinto Filho, J. L. O., Gonçalves, G. L. \& Lunes, A. R. S. (2019). Caracterização socioeconômica e ambiental da população das comunidades rurais da Chapada do Apodi/RN. Geosul, 34(71), 687-712.

Schneider, S. (2003). Teoria social, agricultura familiar e pluriatividade. Revista Brasileira de Ciência do Solo, 18(51), 99-121.

Silva, J. R. \& Jesus, P. (2010). Os desafios do novo rural e as perspectivas da agricultura familiar no Brasil. In: (Anais). Congresso Norte e Nordeste de Pesquisa e Inovação, Maceió: Anais... Maceió, Instituto Federal de Alagoas, 1-12.

Silva, R. N. (2013). Pluriatividade na agricultura familiar tradicional do estado de Mato Grosso. Dissertação de Mestrado, Universidade Católica Dom Bosco, MS, Brasil.

Silva, A. J. (2016). Agricultura familiar e a desterritorialização/desterritorialização/reterritorialização provocada pelo agronegócio no cerrado piauiense: hibridismo sociocultural marginal em Uruçuí. Tese de Doutorado, Universidade Federal do Piauí, PI, Brasil.

Silva, R. M. A., Aquino, J. R., Costa, F. B. \& Nunes, E. M. (2020). Características produtivas e socioambientais da agricultura familiar no Semiárido brasileiro: evidências a partir do Censo Agropecuário de 2017. Sociedade e ambiente no Semiárido: controvérsias e abordagens, (55), $314-338$.

Silva, A. J. (2021). Os desafios da agricultura familiar do cerrado piauiense. Revista da Academia de Ciências do Piauí, 2(2), 171-190. 
Research, Society and Development, v. 10, n. 15, e90101522727, 2021

(CC BY 4.0) | ISSN 2525-3409 | DOI: http://dx.doi.org/10.33448/rsd-v10i15.22727

Sousa, S. K. A., Negrão, H. P. M., Cunha, L. S. C., Fernandes, T. F. S., Mercês, J. K. R., Pereira, W. C., Nascimento, E. B. N., Galdino, M. S. S. \& Silva, A. C. R. (2020). Socioeconomic profile of cassava flour producers: a study on Vila de Igarapé-Açu, Capitão Poço, Pará, Brazil. Communications in plants Sciences, 10, 27-31.

Souza, F. M. (2012). Caracterização socioeconômica e ambiental de produtos florestais não madeireiros de famílias agroextrativistas em quatro municípios de Goiás. Dissertação de Mestrado, Universidade de Brasília, DF, Brasil.

Valadares, A. A., Ferreira, B., Lambais, G. B. R., Martins, L. R. \& Galiza, M. (2016). Os significados da permanência no campo: vozes da juventude rural organizada. In: Silva, E.R. A. \& Botelho, R. U. (Orgs.). Dimensões da experiência juvenil brasileira e novos desafios às políticas públicas (pp. 59-94). Brasília: Ipea.

Wanderley, M. N. B. (2013). Juventude rural: vida no campo e projetos para o futuro. EDUFPE.

Welch, C. \& Fernandes, B. M. (2008). Agricultura e mercado: campesinato e agronegócio da laranja nos EUA e Brasil. In: Paulilo, E.T. \& Fabrini, J.E. (Orgs.). Campesinato e territórios em disputa (pp. 161-190). São Paulo: Expressão Popular.

Zachow, M. \& Plein, C. (2018). A gestão como característica da agricultura familiar. Brazilian Journal of Development, 4(6), 3318-3334. 